\title{
Greener Analytical Method for Determination of Iodine Number of Edible Oils
}

\author{
Thidarat Kruatian ${ }^{1,2} \&$ Kritsana Jitmanee ${ }^{1,2,3}$ \\ ${ }^{1}$ Department of Chemistry, Faculty of Science, Chiang Mai University, Chiang Mai, Thailand \\ ${ }^{2}$ Research Laboratory for Analytical Instrument and Electrochemistry Innovation, Faculty of Science, Chiang \\ Mai University, Chiang Mai, Thailand \\ ${ }^{3}$ Research Center on Chemistry for Development of Health Promoting Products from Northern Resources, \\ Faculty of Science, Chiang Mai University, Chiang Mai, Thailand \\ Correspondence: Kritsana Jitmanee, Department of Chemistry, Faculty of Science, Chiang Mai University, \\ Chiang Mai 50200, Thailand. Tel: 66-5394-3341. E-mail: kritsana.j@cmu.ac.th
}

Received: September 5, 2020

Accepted: September 26, $2020 \quad$ Online Published: October 20, 2020

doi:10.5539/jfr.v9n6p36

URL: https://doi.org/10.5539/jfr.v9n6p36

\begin{abstract}
A greener analytical method for determination of iodine number (IN) of oils is presented. As per the AOAC standard method, a large amount of solvent and reagent was used, and long incubation time was required. This research is aimed at using less amount of solvent and reagent, less sample weight, and shorten the analysis time by using the modified titrimetric AOAC standard method. The study showed that by reducing the sample size, the amount of reagent could be decreased to $1.00 \mathrm{~mL}$ and the reaction time of $1 \mathrm{~min}$ is enough for completion of the reaction. The amount of reagent used was at least 25 times less than that of the classical method. There was no significant difference at $95 \%$ confidence level between the results obtained by the proposed method and the standard method, and both results correlated well. The present method can be applied to edible oils commonly found in the market (iodine number range of 6.0 to 130).
\end{abstract}

Keywords: iodine number, edible oil, green analytical method, modified titrimetric method

\section{Introduction}

Nowadays, iodine number (IN) is one of the great interest parameters for measuring the degree of unsaturation of oil or fat and quickly indicating the group to which the oil belongs to. It is defined as the number of halogen in centigram, expressed as iodine, which is absorbed by one gram of oil sample (percent iodine absorption). The higher iodine number, the more unsaturated fatty acid parts are present in oil. The interesting application of iodine number is its use as a parameter in process control as well as a quality parameter in traded palm oil product. It is used as a guidance tool for the purchasing of raw materials and controlling hydrogenation reaction (Weiss, 1970). It is also used to investigate the properties of vegetable oil that used to produce biodiesel that will affect some properties of biodiesel, such as viscosity, cloud point, and storage stability which are changed due to the oxidation and polymerization reactions of double bonds in the oil. Moreover, since oil of high iodine number will contain high content of unsaturated bonds in fatty acids, it indicates the nutritional value (Knothe, 2002).

Several analytical techniques for determination of iodine number of edible oils have been reported. Some studies are undertaking by measuring the amount of remaining reagent from the reaction by using ion selective electrode (ISE) in potentiometric method (Honda \& Kashimoto, 1978; Mahapatra, 2011) or measuring the absorbance of the remaining reagent (Kamson, 1986; Lee \& Pollard, 1984), which is simple but still using large amount of reagent and solvent. Some papers also introduced flow injection techniques (FI) to make a more comfortable and faster analysis (Thomaidis \& Georgiou, 2000). However, though the method provided automatic measurement the continuous flowing of reagent still generated large amounts of waste solution. Furthermore, nuclear magnetic resonance(NMR), near infrared(NIR), and Furior transform infrared(FT-IR) spectroscopic techniques have been proposed (Baeten \& Aparicio, 2000; Che Man \& Setiowaty, 1999; Foca et al., 2016; Hendl, 2001; Yang et al., 2005). The gas chromatographic method is an alternative method for determination of IN as per AOCS Cd1c-85 (Firestone, 1989). By this method, IN is calculated from the fatty acid composition in the oil sample. With this technique, quantification of different free fatty acids can be made simply. However, it involves 
a complicated mathematical calculation, high-cost instrument, and well operation skill.

The determination of iodine number of edible oils according to the AOAC standard methods (Helrich, 1990) is carried out by using the titration method. An oil sample is analyzed by reacting with Hanus solution (iodine monobromide in glacial acetic acid) or Wij's solution (iodine monochloride), and then the amount of the remaining reagent is determined. This titrimetric method is simple and requires only general laboratory skills and apparatus. However, as per the AOAC titrimetic method, $25 \mathrm{~mL}$ of $\mathrm{IBr}$ reagent and $10 \mathrm{~mL}$ of chlorinated solvents per analysis is required with 30 to $60 \mathrm{~min}$ incubation time.

For many years, the green chemistry movement has been promoting ways to reduce the risks of chemical use to humans and the environment. The main concept of green chemistry is the application of chemistry skills and knowledge to reduce or eliminate the use and/or generation of hazardous substances (Anastas, 1999; De Marco et al., 2019).

In this research, it is aimed to modify the titrimetric AOAC standard method for the determination of iodine number of edible oils by using less amounts of sample and reagent, and shorter incubation time. The experimental conditions were studied for reducing the amount of reagent and solvent, using short analysis time, and avoiding the usage of chlorinated solvent.

\section{Method}

\subsection{Materials and Reagents}

All chemicals, i.e., glacial acetic acid, potassium iodide, starch soluble, dichloromethane (as per AOAC titrimetric method), n-propanol, iso-octane, and oleic acid were analytical reagent grade. Standard solutions of $0.1 \mathrm{M}$ and $0.005 \mathrm{M}$ sodium thiosulfate were prepared by dissolving in deionized (DI) water and standardized against potassium iodate. Hanus solution (iodine monobromide, $\mathrm{IBr}$ ) concentration of $0.10 \mathrm{M}$ was prepared with glacial acetic acid according to the AOAC method (Helrich, 1990). The Hanus solution is stable for at least 1 month.

\subsection{Sample Preparation}

Nine samples of commercially available edible oil were purchased from local stores in Chiang Mai, Thailand, with IN range from 5 to 130 . These included coconut, palm, olive, rice bran, sesame, canola, corn, sunflower, and soybean oils. Weighed $0.10 \mathrm{~g}$ of sample and dissolved it with iso-octane to $10 \mathrm{~mL}$. One-mL aliquot of this sample solution (0.010 $\mathrm{g}$ sample) is used for analysis.

\subsection{Determination of IN by AOAC Titrimetric Method (Helrich, 1990)}

The AOAC titrimetric method was slightly modified. An aliquot of $0.25 \mathrm{~g}$ oil sample was dissolved in $10 \mathrm{~mL}$ of dichoromethane (instead of chloroform), follows by adding $25 \mathrm{~mL}$ of IBr solution. Shook it and incubated in the dark for $30 \mathrm{~min}$. Then, added $15 \% \mathrm{w} / \mathrm{v}$ potassium iodide solution $10 \mathrm{~mL}$. Titrated with $0.1 \mathrm{M}$ sodium thiosulfate to pale yellow. Added few drops of starch indicator and continued titrating until the blue color entirely disappears. Blank determination was conducted similarly but without oil. The iodine number was then calculated using equation (1).

$$
\mathrm{IN}=[(\mathrm{VB}-\mathrm{VS}) \times \mathrm{M} \times 12.69] / \mathrm{W}
$$

Where $\mathrm{V}_{\mathrm{B}}=\mathrm{mL} \mathrm{Na}_{2} \mathrm{~S}_{2} \mathrm{O}_{3}$ used for blank determination, $\mathrm{V}_{\mathrm{S}}=\mathrm{mL} \mathrm{Na} \mathrm{S}_{2} \mathrm{O}_{3}$ used for sample determination, $\mathrm{M}=$ molarity of $\mathrm{Na}_{2} \mathrm{~S}_{2} \mathrm{O}_{3}, \mathrm{~W}=$ weight of sample $(\mathrm{g})$

\subsection{Greener Titrimetric Method for Determining Iodine Number}

This method was modified from the AOAC titrimetric method to be a small scale titration. Weighed $0.10 \mathrm{~g}$ sample and dissolved it with iso-octane to $10 \mathrm{~mL}$. One-mL aliquot of this solution $(0.010 \mathrm{~g}$ sample $)$ was mixed with $\mathrm{IBr}$ solution $1 \mathrm{~mL}$. Shook it and incubated in the dark for $1 \mathrm{~min}$. Then, added $6 \% \mathrm{w} / \mathrm{v}$ potassium iodide solution $1 \mathrm{~mL}$. Titrated with $0.005 \mathrm{M}$ sodium thiosulfate to pale yellow. Added few drops of starch indicator and continued titrating until blue entirely disappears. Conducted blank determination. The iodine number was calculated using equation (1).

\section{Results and Discussion}

\subsection{Optimization Studies}

The parameters which affected analytical performance and the optimum condition are presented in Table 1 . 
Table 1. Optimization of the conditions of downscaled titrimetry

\begin{tabular}{ll}
\hline Parameters & Condition \\
\hline Sample weight & $0.010 \pm 0.001 \mathrm{~g}$ \\
IBr solution & \\
- Concentration & $0.10 \mathrm{M}$ \\
- Volume & $1.00 \mathrm{~mL}$ \\
Incubation time & $1 \mathrm{~min}$ \\
Solvent & Iso-octane $1.0 \mathrm{~mL}$ \\
\hline
\end{tabular}

\subsubsection{Effect of Type and Amount of Solvent}

Chloroform has long been used for dissolving oil sample and its use has been banned in some countries. n-Propanol was used for an online spectrophotometric approach (Thomaidis \& Georgiou, 2000) since it readily mixed with $\mathrm{IBr}$ solution. However, when this mixture is mixed with an aqueous solution of potassium iodide, the emulsion is formed. In this work, dichloromethane, n-propanol, and iso-octane (Takeshita et al., 1994) were compared for use in the determination of IN. Although dichloromethane is a chlorinated solvent, it was used for comparison purpose. The results as shown in Table 2 indicated that there was no significant difference in the iodine number by using these solvents. Iso-octane was readily mixed with $\mathrm{IBr}$ solution, did not form an emulsion with oil and aqueous solution. To avoid emulsion forming and to eliminate the usage of chlorinated solvent, iso-octane was chosen for dissolving oil samples.

Table 2. The determination of IN using different solvents ( $\mathrm{n}=3$ )

\begin{tabular}{lllll}
\hline \multirow{2}{*}{ Type of solvent } & \multicolumn{2}{l}{ Palm oil } & \multicolumn{2}{l}{ Soybean oil } \\
\cline { 2 - 5 } & IN & \%RSD & IN & \%RSD \\
\hline Dichloromethane & 53.6 & 2.6 & 131.7 & 2.2 \\
n-Propanol & 58.5 & 0.7 & 136.5 & 1.1 \\
iso-Octane & 55.4 & 0.3 & 125.6 & 0.9 \\
\hline
\end{tabular}

It was also attempted to reduce the volume of solvent used for dissolving oil samples. By utilizing the procedures described in section 2.4 but using the different volumes of solvent, iso-octane, i.e., $1.00,5.00$, and $10.00 \mathrm{~mL}$, the resulting iodine numbers of oil samples are shown in Table 3. It was found that there was no significant difference observed in the IN of these oil samples by using $1.00,5.00$, and $10.00 \mathrm{~mL}$ of solvent. Therefore, 1.00 $\mathrm{mL}$ of iso-octane was selected for dissolving $0.01 \mathrm{~g}$ of oil.

Table 3. Effect of the amount of solvent for IN determination of palm and soybean oils. $(n=3)$

\begin{tabular}{lllll}
\hline \multirow{2}{*}{ Volume of solvent $(\mathrm{mL})$} & \multicolumn{2}{l}{ Palm oil } & \multicolumn{2}{l}{ Soybean oil } \\
\cline { 2 - 5 } & IN & \%RSD & IN & \%RSD \\
\hline 1.00 & 55.6 & 0.5 & 127.7 & 0.9 \\
5.00 & 56.6 & 1.0 & 129.6 & 1.2 \\
10.00 & 56.2 & 1.1 & 128.2 & 1.1 \\
\hline
\end{tabular}

\subsubsection{Effect of Incubation Time}

The rate and extent of the halogenation reaction depend on incubation or reaction time (Earle \& Milner, 1939; Markley, 1947). As suggested in the AOAC standard method, the higher iodine number of oil has required the longer the incubation time to complete the reaction. The effect of incubation time ranges from 1 to 30 min was investigated as shown in Table 4. The results were shown that there was no significant difference in iodine number of both palm oil and soybean oil for the analysis employing the incubation time of 1, 5, 15, and 30 min (one-way ANOVA test; F-cal $=0.074$, F-crit $=6.59$ for palm oil, and F-cal $=0.013$, F-crit $=6.59$ for soybean oil ). Therefore, the incubation time of $1 \mathrm{~min}$ was chosen. It should be noted that this incubation time is appropriate for $0.01 \mathrm{~g}$ of oil having iodine number equal or less than that of soybean oil. 
Table 4. The effect of reaction time for IN determination of palm and soybean oils. ( $n=3$ )

\begin{tabular}{lllll}
\hline \multirow{2}{*}{ Incubation time (min) } & \multicolumn{2}{l}{ Palm oil } & \multicolumn{2}{l}{ Soybean oil } \\
\cline { 2 - 5 } & IN & \%RSD & IN & \%RSD \\
\hline 1 & 57.6 & 0.5 & 127.9 & 1.2 \\
5 & 57.5 & 0.2 & 128.4 & 0.8 \\
15 & 57.4 & 0.2 & 128.9 & 1.0 \\
$30 *$ & 56.8 & 1.3 & 129.7 & 0.9 \\
\hline
\end{tabular}

* as per AOAC method

\subsubsection{Effect of the Weight of Sample}

As per AOAC method, $25.00 \mathrm{~mL}$ of $\mathrm{IBr}$ solution is recommended for $5.00 \mathrm{~g}$ of oil sample, therefore, for $1.00 \mathrm{~mL}$ of this reagent should be reacted quantitatively with $0.100 \mathrm{~g}$ of sample. The weight of soybean oil ca. $0.01,0.02$, and $0.05 \mathrm{~g}$ were studied for its effect on IN. The IN (mean \pm S.D., $\mathrm{n}=3$ ) of $131.8 \pm 3.3,102.1 \pm 0.2$, and $45.9 \pm$ 0.1 were obtained with the sample weight of $0.01,0.02$, and $0.05 \mathrm{~g}$, respectively. The reaction of IBr with sample requires 50-60\% excess of this reagent as mentioned in AOAC method (Helrich, 1990). Therefore, sample weight of $0.010 \mathrm{~g}$ of soybean oil and other oils with IN less than that of the soybean oil is appropriate for reacting with $1.00 \mathrm{~mL}$ of $0.10 \mathrm{M} \mathrm{IBr}$ solution.

\subsubsection{Effect of Concentration and Volume of IBr Solution}

Though the concentration of $\mathrm{IBr}$ solution of $0.10 \mathrm{M}$ is stated in AOAC method, it was investigated whether or not the lower concentration of this reagent can be used. The effect of concentration of $\mathrm{IBr}$ solution was investigated by analysis of soybean oil with different concentrations of $\mathrm{IBr}$ solution ranged from 0.025 to 0.100 $\mathrm{M}$, IN (mean $\pm \mathrm{SD}, \mathrm{n}=3$ ) obtained were $44.5 \pm 1.1,82.5 \pm 0.8,109.5 \pm 1.5$, and $127.3 \pm 1.3$, respectively. This results are also in consistency with the analysis of palm oil and sunflower oil at IBr concentration of 0.050 and $0.10 \mathrm{M}$. The volume of $\mathrm{IBr}$ solution was also investigated and the results are shown in Table 5.

Table 5. The effect of volume of IBr solution for determination of IN $(n=3)$

\begin{tabular}{lllll}
\hline \multirow{2}{*}{ Sample } & \multicolumn{3}{l}{ Volume of Hanus solution $(\mathrm{mL})$} & IN \\
\cline { 2 - 4 } & 1.00 & 1.50 & 2.00 & by AOAC method \\
\hline Coconut & $5.6 \pm 1.4$ & $6.6 \pm 1.3$ & $3.4 \pm 0.7$ & $6.5 \pm 0.7$ \\
Oleic acid & $90.2 \pm 1.3$ & $91.1 \pm 2.4$ & $92.8 \pm 4.5$ & $90.3 \pm 1.1$ \\
Linolenic acid & $143.1 \pm 1.0$ & $153.3 \pm 3.5$ & $157.8 \pm 6.0$ & $154.9 \pm 1.0$ \\
Soybean & $121.7 \pm 4.2$ & $132.1 \pm 3.5$ & $135.0 \pm 3.7$ & $124.6 \pm 1.5$ \\
Ricebran & $97.7 \pm 3.2$ & $98.5 \pm 3.6$ & $104.8 \pm 4.2$ & $100.1 \pm 1.2$ \\
Sunflower & $116.5 \pm 1.6$ & $119.5 \pm 2.3$ & $135.2 \pm 1.7$ & $126.2 \pm 1.1$ \\
Palm & $59.1 \pm 2.0$ & $58.7 \pm 2.6$ & $61.3 \pm 2.4$ & $58.8 \pm 1.0$ \\
\hline
\end{tabular}

It is shown in Table 5 that the volume of reagent had affected on the IN of linoleic acid, soybean oil, rice bran oil, and sunflower oil. For oil samples having IN less than $100,1.00 \mathrm{~mL}$ of reagent is appropriate. However, for oil having IN more than $100,2.00 \mathrm{~mL}$ of reagent should be used.

\subsection{Real Sample Analysis}

The proposed greener titrimetric method was applied for determination of IN of real oil samples. Oleic acid and nine vegetable oil samples were subjected to the analysis. The analytical results are shown in Table 6 . To test whether or not the results obtained by both methods were different, the paired t-test was performed. The observed $\mathrm{t}$-value, $\mathrm{t}_{\mathrm{cal}}=0.011$, was less than the critical $\mathrm{t}$-value, $\mathrm{t}_{\text {crit }}=2.10$, therefore, there was no significant difference between the results obtained by the proposed method and the AOAC standard method. The developed method has superior advantages on at least 25 folds reducing the amounts of reagent and analysis time, and consequently producing very small amounts of waste solution. 
Table 6. Analytical results for IN determination of edible oils by greener titrimetric method $(n=3)$

\begin{tabular}{llllll}
\hline \multirow{2}{*}{ Oil } & \multicolumn{2}{l}{ AOAC standard method } & \multicolumn{2}{l}{ Proposed method } & \multirow{2}{*}{ \% Difference } \\
\cline { 2 - 5 } & IN & \%RSD & IN & \%RSD & \\
\hline Coconut & 7.5 & 17.1 & 6.5 & 11.1 & 14 \\
Palm & 59.0 & 0.3 & 58.8 & 1.7 & 1 \\
Olive & 82.1 & 0.6 & 84.4 & 0.9 & 3 \\
Rice bran & 100.1 & 0.5 & 101.9 & 2.0 & 2 \\
Sesame & 108.8 & 0.4 & 106.2 & 1.3 & 2 \\
Canola & 109.9 & 0.6 & 106.5 & 2.3 & 3 \\
Corn & 112.3 & 0.7 & 110.2 & 2.1 & 2 \\
Sunflower & 126.2 & 0.5 & 127.3 & 0.4 & 1 \\
Soybean & 126.8 & 0.8 & 124.6 & 1.2 & 2 \\
Oleic acid & 85.9 & 0.5 & 90.3 & 1.3 & 5 \\
\hline
\end{tabular}

\section{Conclusions}

The greener titrimetric method for determination of iodine number of edible oils provided various advantages such as short analysis time, low reagent and solvent consumption. By reducing the sample size, reagent, solvent, and reaction time could be dramatically reduced. The amount of solvent and reagent used were at least 25 times less than that of the classical standard method. By using simple titration method, there is no significant difference between the results obtained by the proposed method and the standard method for the IN in the range of $6.0-130$.

\section{Acknowledgements}

The authors gratefully acknowledge the financial support of this research by The Research Professional Development Project under the Science Achievement Scholarship of Thailand (SAST), Department of Chemistry, Research Laboratory for Analytical Instrument and Electrochemistry Innovation and Research Center on Chemistry for Development of Health Promoting Products from Northern Resources, Faculty of Science Chiang Mai University and the Graduate School of Chiang Mai University.

\section{References}

Anastas, P. T. (1999). Green Chemistry and the Role of Analytical Methodology Development. Critical Reviews in Analytical Chemistry, 29(3), 167-175. https://doi.org/10.1080/10408349891199356

Baeten, V., \& Aparicio, R. (2000). Edible oils and fats authentication by Fourier transform Raman spectrometry. Biotechnology Agronomy Society and Environment, 4, 196-203.

Che Man, Y. B., \& Setiowaty, G. (1999). Multivariate calibration of Fourier transform infrared spectra in determining iodine value of palm oil products. Food Chemistry, 67(2), 193-198. https://doi.org/10.1016/S0308-8146(99)00102-8

De Marco, B. A., Rechelo, B. S., Tótoli, E. G., Kogawa, A. C., \& Salgado, H. R. N. (2019). Evolution of green chemistry and its multidimensional impacts: A review. Saudi Pharmaceutical Journal, 27(1), 1-8. https://doi.org/10.1016/j.jsps.2018.07.011

Earle, F. R., \& Milner, R. T. (1939). Study of the kaufmann method for determining iodine numbers. Journal of the American Oil Chemists' Society, 16, 69-71. https://doi.org/10.1007/BF02543242

Firestone, D. (1989). Official Methods and Recommended Practices of the American Oil Chemists'Society (4th ed.). method Cd 1c-85. Champaign, IL: AOCS.

Foca, G., Ferrari, C., Ulrici, A., Ielo, M. C., Minelli, G., \& Fiego, D. P. L. (2016). Iodine Value and Fatty Acids Determination on Pig Fat Samples by FT- NIR Spectroscopy: Benefits of Variable Selection in the Perspective of Industrial Applications. Food Analytical Methods, 9, 2791-2806. https://doi.org/10.1007/s12161-016-0478-6

Helrich, K. (1990). Official Methods of Analysis of the AOAC (15th ed.). methods 920.158 and 920.159. Arlington, VA: AOAC.

Hendl, O., Howell, J. A., Lowery, J., \& Jones, W. (2001). A rapid and simple method for the determination of iodine values using derivative Fourier transform infrared measurements. Analytica Chimica Acta, 427, 75-81. https://doi.org/10. 1016/ S0003-2670(00)01193-4 
Honda, A., \& Kashimoto, M. (1978). Potentiometric determination of iodine values of oils with an iodide-selective electrode. Analytica Chimica Acta, 97, 391-394. https://doi.org/10.1016/S0003-2670(01)93447-6

Knothe, G. (2002). Structure indices in FA chemistry. How relevant is the iodine value?. Journal of the American Oil Chemists' Society, 79, 847-854. https://doi.org/10.1007/s11746-002-0569-4

Kamson, O. F. (1986). Spectrophotometric determination of iodate, iodide and acids by flow- injection analysis. Analytica Chimica Acta, 179, 475-479. https://doi.org/10.1016/S0003-2670(00)84495-5

Lee, C.C., \& Pollard, B.D. (1984). Determination of iodine value of fatty acid by a flow injection method. Analytica Chimica Acta, 158, 157-167. https://doi.org/10.1016/S0003-2670(00)84824-2

Markley, K. S. (1947). Fatty acids: Their Chemistry and Physical Properties. New York: Interscience Publishers, Inc. pp. 334-336.

Mahapatra, P. K., Singh, M., Pandey, L., \& Singla, M. L. (2011). Electro-chemicalsystem for the determination of unsaturation of edible oils. Food Chemistry, 126(3), 1505-1507. https://doi.org/10.1016/j.foodchem.2010.11.109

Soares, S., \& Rocha, F. (2018). Fast spectrophotometric determination of iodine value in biodiesel and vegetable Oils. Journal of the Brazilian Chemical Society, 29(8), 1701-1706. https://doi.org/10.21577/0103-5053.20180044

Takeshita, Y., Yoshida, H., Hinata, K., \& Iimura, K. (1994). Transactions of the Kokushikan University. Faculty of Engineer, 18, 9-13.

Thomaidis, N. S., \& Georgiou, C. A. (2000). Direct parallel flow injection multichannel spectrophotometric determination of olive oil iodine value. Analytica Chimica Acta, 405, 239-245. https://doi.org/10.1016/S0003-2670(99)00711-4

Weiss, T. J. (1970). Food Oils and Their Uses. Washington, D.C.: The AVI publishing company.

Yang, H., Irudayaraj, J., \& Paradkar, M. M. (2005). Discriminantanalysis of edibleoils and fats by FTIR, FT-NIR and FT-Ramanspectroscopy. Food Chemistry, 93, 25-32. https://doi.org/10.1016/j.foodchem.2004.08.039

\section{Copyrights}

Copyright for this article is retained by the author(s), with first publication rights granted to the journal.

This is an open-access article distributed under the terms and conditions of the Creative Commons Attribution license (http://creativecommons.org/licenses/by/4.0/). 